\title{
Implicações da experimentação como aporte em atividades por problematização para compreensão do fenômeno corrosão
}

\author{
Regina Célia Barbosa de Oliveira ${ }^{1}$ \\ Carla Carvalho de Melo $^{2}$ \\ Agilson Nascimento de Souza ${ }^{3}$
}

\begin{abstract}
RESUMO
$\mathrm{O}$ objeto de estudo deste trabalho diz respeito ao ensino-apredendizagem de conceitos químicos junto a estudantes do ensino médio, a fim de analizar contribuições da experimentação em atividades problematizadoras, voltadas para a significação de conceitos químicos associados à corrosão. Foram gravados e analisados, qualitativamente, áudios de entrevistas semiestruturadas e de observação participante. As relações observadas dos(as) participantes demonstraram articulações entre conteúdos químicos e o tema corrosão, com um avanço no estado de compreensão de tal fenômeno, o que sugeriu a (re)construção de conhecimentos e conexões com outros contextos, potencializando o desenvolvimento de sua aprendizagem, no sentido de abstração do tema em estudo. Portanto, a estratégia de ensino contribuiu para os processos cognitivos e argumentativos, nos quais a experimentação se fez propícia às articulações entre o conhecimento químico e o contexto estudado, a partir das interações promovidas em meio à problematização, conduzindo os(as) estudantes a alcançarem significação conceitual.
\end{abstract}

PALAVRAS-CHAVE: Experimentação. Problematização. Significação conceitual. Corrosão.

\footnotetext{
${ }^{1}$ Doutora. Universidade Federal de Pernambuco, Caruaru, Pernambuco, Brasil. Orcid: http://orcid.org/0000-00015574-8516. E-mail: rcbgina@gmail.com.

${ }^{2}$ Mestra. Universidade Federal de Pernambuco, Caruaru, Pernambuco, Brasil. Orcid: http://orcid.org/0000-00031560-5945. E-mail: carla melo92@ hotmail.com.

${ }_{3}^{3}$ Mestre. Universidade Federal de Pernambuco, Caruaru, Pernambuco, Brasil. Orcid: http://orcid.org/0000-00024572-1712. E-mail: agilson_ns@yahoo.com.br.
} 


\title{
Implications of experimentation as a contribution to problematized activities to understand the corrosion phenomenon
}

\begin{abstract}
This study comprises an investigation of the teaching-learning process regarding chemical concepts in a group of basic education students, in order to analyze experimentation contributions in problematizing activities, focused on the meaning of chemical concepts associated with corrosion. Audios from semi-structured interviews and participant observations were recorded and qualitatively analyzed. The observed participant relationships demonstrated links between chemical content and the corrosion theme, advancing the understanding of this phenomenon, suggesting knowledge (re)construction and connections with other contexts, enhancing student learning development, in the context of abstraction of the investigated subject. Therefore, the applied teaching strategy contributed to cognitive and argumentative processes, in which experimentation was conducive to articulations between chemical knowledge and the studied context from interactions promoted by problematization, allowing students to reach conceptual significance.
\end{abstract}

KEYWORDS: Experimentation. Problematization. Conceptual significance. Corrosion.

\section{Implicaciones de la experimentación como contribución a actividades problemáticas para comprender el fenómeno de corrosión}

\section{RESUMEN}

El objeto de estudio de este trabajo hace referencia a la enseñanza de conceptos químicos a estudiantes de secundaria, con el fin de analizar los aportes de la experimentación en actividades problematizadoras, enfocadas en el significado de conceptos químicos asociados a la corrosión. Cualitativamente fueron grabados y analizados audios de entrevistas semiestructuradas y de observación participante. Las relaciones observadas de los participantes demostraron vínculos entre el contenido químico y el tema de la corrosión, con un avance en el estado de comprensión de este fenómeno, lo que sugirió la (re)construcción de conocimientos y conexiones con otros contextos, potenciando el desarrollo 
del aprendizaje, en el sentido de abstracción del tema en estudio. Por lo tanto, la estrategia de enseñanza contribuyó a los procesos cognitivos y argumentativos, en los que la experimentación propició las articulaciones entre el conocimiento químico y el contexto estudiado, a partir de las interacciones promovidas en medio de la problematización, llevando a los estudiantes a alcanzar una significación conceptual.

PALABRAS CLAVE: Experimentación. Problematización. Significado conceptual. Corrosión.

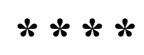

\section{Introdução}

Dentre algumas situações de ensino-aprendizagem, é recorrente a dificuldade de estudantes do ensino médio, referente a aplicabilidade da Química em contextos cotidianos (POZO; CRESPO, 2009). Apesar de algumas iniciativas, obstáculos dessa natureza ainda fazem parte da rotina educacional brasileira. Santos et al. (2013) atribuem tal condição a modelos de ensino que levam à memorização de informações, fórmulas e conhecimentos que limitam a aprendizagem dos(as) estudantes. Consoante com o referido autor, acreditamos que tais modelos podem desencadear o desinteresse pelo estudo da disciplina em voga.

Guimarães (2009) ressalta que conteúdos fragmentados, sem relacão com os conhecimentos prévios do(a) estudante, aliados a uma participação qualitativamente precária, muito presente no ensino tradicional, tendem a dificultar o processo de aprendizagem significativa. À luz da teoria da Aprendizagem Significativa de Ausubel (1963), o conhecimento prévio do(a) estudante é o fator primordial para que a aprendizagem seja significativa. Outro aspecto que contempla a teoria diz respeito à criticidade do estudante em meio às exigências da sociedade contemporânea (MOREIRA, 2010).

Estrategicamente, atividades experimentais em ensino de ciências configuram um recurso didático cuja função seria auxiliar os(as) estudantes 
na compreensão de conceitos relacionados aos fenômenos estudados, contribuindo no processo investigativo, buscando significar tais conceitos (ZANON; UHMANN, 2012). Tradicionalmente, em atividades experimentais, estudantes seguem roteiros previamente elaborados e suas ações são conduzidas por instruções docentes ou mesmo do texto, contrapondo-se às necessidades emergentes de ensino-aprendizagem (OLIVEIRA; HARTWIG; FERREIRA, 2010).

Sendo essa uma prática comum em nossos dias, acenamos para necessidade de incentivos a estratégias que conduzam à reflexão, superando aspectos reducionistas de ilustração e comprovação de teorias. Nesse sentido, Francisco Júnior (2008) observa que o conhecimento se constrói em um processo dialógico, em que docentes, por meio da problematização, oportunizam estudantes a pensar e discutir a relação de conceitos químicos de maneira desfragmentada e contextualizada, projetando possibilidades de melhor compreensão de questões sociais.

Nessa perspectiva, pensamos que a utilização de experimentação como aporte em atividades por problematização pode se constituir uma alternativa para a construção significativa do conhecimento e consideramos a corrosão um tema propicio para contextualizar o conhecimento químico junto a um grupo de estudantes do ensino médio, dada a dificuldade de aprendizagem de conceitos associados a tal fenômeno. Conforme Cachapuz (2005), os problemas devem ser propostos ou assumidos por estudantes, apresentando sentido pessoal, constituindo-se um desafio intelectual. Francisco Júnior, Ferreira e Hartwig (2008) acrescentam que a experimentação deve instigar o(a) estudante por meio da curiosidade e do desafio, levando-o(a) a refletir sobre questões pertencentes à sua realidade e propor ações mais efetivas, que contribuam para a solução de problemas.

Em estudo envolvendo o tema "Maresia" no ensino de eletroquímica, Sanjuan et al. (2009) mencionam dificuldades de abstração de conceitos químicos associados à corrosão, como oxidação, redução e número de oxidação. Corroborando com nossa percepção, Merçon, Guimarães e Mainier 
(2004) observam que a contextualização de conteúdos da Química em torno do tema corrosão, favorece a associação de conceitos científicos a aspectos sociais, econômicos, ambientais e históricos, conduzindo discentes à formação cidadã (MERÇON; GUIMARÃES; MAINIER, 2011).

Sendo assim, surgiu a inquietação: Como o uso da experimentação, em atividades problematizadoras, poderia contribuir para a significação de conceitos químicos na compreensão do fenômeno corrosão, junto a um grupo de estudantes do ensino médio?

Para responder à questão supracitada, buscamos analisar as decorrências do uso da experimentação em atividades problematizadoras, voltadas para a significação de conceitos químicos associados à corrosão. Para tanto, buscamos identificar situações em que os(as) estudantes estabeleçam conexões coerentes entre conceitos químicos e o contexto proposto e verificar se eles(as) conseguem realizar inferências apropriadas quando da compreensão de fenômenos cotidianos relacionados à corrosão.

\section{Experimentação em atividades por problematização como recurso à aprendizagem significativa}

Tradicionalmente, a aprendizagem de conceitos químicos na educação básica tem apresentado resultados pouco satisfatórios. Ausência de contextualização da química dificulta a articulação de conceitos, prevalecendo processos de memorização (LIMA et al. 2000). Corroborando com tais autores, Binsfeld e Auth (2011) observam que a ausência de relação entre os conteúdos abordados e o contexto discente, tende a dificultar a significação do conhecimento.

Contrapondo-se à retórica do ensino tradicional, Kato e Kawasaki (2011) usam estratégias de ensino por contextualização, visando aproximação do ensino-aprendizagem à realidade dos(as) estudantes, superando abordagens fragmentadas, distanciadas do contexto discente, mas presentes nos currículos. 
Contribuindo para o debate, Chassot (2014), resalta que para uma aproximação entre conceitos e contextos, o ensino de Química deve ser orientado sob a percepção de sua função social, em que discentes perceberiam a articulação de conceitos químicos em contextos diversos, podendo atribuir significação à aprendizagem. Sobre esse aspecto, Wharta (2013) opõe-se à utilização de situações do cotidiano como forma de ilustrar e exemplificar a aplicação de conceitos químicos, sem que ocorra a problematização e análise numa dimensão mais sistêmica como parte do mundo físico e social.

Os autores supracitados coadunam com as orientações educacionais complementares aos Parâmetros Curriculares Nacionais (Brasil, 2002) que sugerem abordagem contextualizada para condução discente à maior participação no processo educativo, propiciando aprendizagem significativa. Segundo Ausubel, quando uma nova informação interage com um conceito subsunçor, já existente na estrutura cognitiva do(a) estudante e, por meio dessa interação, a informação é ancorada e assimilada, ao mesmo tempo que modifica o subsunçor, caracteriza-se uma aprendizagem significativa. Dois princípios estão associados a esse processo: a diferenciação progressiva, quando as idéias são apresentadas progressivamente das mais gerais para as mais específicas e a reconciliação integrativa, explorando a relação entre conceitos e proposições (MOREIRA; MASINI, 2001). Moreira (2005) acrescenta ainda a necessidade de a aprendizagem ser crítica, formadora de cidadãos(ães) melhor inseridos no contexto social.

Nesse sentido, Melo, Oliveira e Nascimento (2019) observam que a utilização da experimentação como aporte de atividades problematizadoras se constitui uma alternativa pertinente para a significação do conhecimento químico, por permitir que discentes assumam protagonismo no processo, aspecto essencial à aprendizagem significativa crítica.

Gonçalves (2005) salienta equívocos de profissionais da educação ao conceberem a experimentação como atividade meramente voltada para confirmação de teorias. Em consonância com o referindo autor, Giani (2010), Silva, Machado e Tunes (2011) e Suart (2014) acrescentam que a 
experimentação nessa perspectiva a tornaria restrita à ilustração e/ou aplicação de roteiros de instruções mecânicas, meramente reprodutivistas.

Baseado em Gonçalves (2005), entendemos que atividades experimentais investigativas, envolvolvem o(a) estudante de modo mais efetivo no processo de aprendizagem, partindo de uma situação problematizadora de interesse do(a) estudante, a fim de que este se motive a aprender.

Em consonância com Gonçalves (2005), acreditamos que atividades experimentais investigativas tendem a conduzir o(a) estudante a um processo de reflexão, construção e significação de conceitos. Sendo assim, tais atividades podem propiciar o desenvolvimento de habilidades de argumentação, o trabalho colaborativo e a socialização dos(as) estudantes, como sugerem Galiazzi e Gonçalves (2004). Em alinhamento com os referidos autores, Zanon e Uhmann (2012), enfatizam que a interação entre estudantes durante as atividades experimentais é aspecto fundamental na construção ou reconstrução de conceitos a partir da exposição de ideias e de novas informações.

Rompendo com as concepções do ensino tradicional, caracteristicamente conteudistas, Binsfeld e Auth (2011) defendem a importância de espaços onde o(a) estudante sinta-se motivado(a) a expressar suas concepções e ser questionador(a), de modo que atue em contextos próximos, compreendendo os limites e possibilidades de seu papel como cidadão(ã). Para facilitar a expressão dessas ideias, destacamos a problematização que, como observa Gonçalves (2005), favorece a explicitação dialógica dos conhecimentos discentes. Esse mesmo pensamento é compartilhado por Guimarães (2009) ao sugerir que a problematização, com vistas à exposição do conhecimento prévio do(a) estudante, por meio da linguagem, exigiria mais que a simples memorização de conceitos e informações.

A inserção da problematização também pode ser realizada pelo uso de situação-problema, definida por Meirieu (1998) como situações 
didáticas nas quais são propostas aos(às) estudantes tarefas que requerem uma aprendizagem clara, alcançada pela superação dos empecilhos à realização da tarefa.

Acerca dessa discussão, Suart (2014) acrescenta que o caminho metodológico trilhado para solucionar a situação-problema seria mais importante que resolvê-la, pois nessa busca estariam envolvidos processos reflexivos, cognitivos e interacionais, considerados como principais ganhos para o grupo envolvido. Zanon e Uhmann (2012) e Suart (2014) enfatizam a função docente como mediadora do processo de ensino-aprendizagem, sendo responsável pela criação de situações que exijam reflexão no decorrer de etapas investigativas e pela inserção da problematização e contextualização dos conteúdos, atrelando observações e discussões teóricas para que os(as) estudantes construam argumentos e hipóteses para a solução da situaçãoproblema. Assim, a atividade docente poderia direcionar a prática para que os novos conhecimentos sejam relacionáveis àqueles que o(a) estudante já possui e, conforme Ausubel (1982, apud Pelizzari et al., 2002), a relação substancial dos novos conteúdos com aspectos relevantes da estrutura cognitiva do(a) estudante conduziria à aprendizagem significativa .

\section{Desenho metodológico}

A pesquisa se configurou uma abordagem qualitativa que, conforme Chizzotti (2010, pág. 84) na análise dos dados procura-se compreender dos participantes "a experiência que eles têm, as representações que formam e os conceitos que elaboram. Esses conceitos manifestos, as experiências relatadas ocupam o centro de referência das análises e interpretações”. Nesse sentido, entendemos a pesquisa qualitativa capaz de dar suporte à extração de informações relevantes para a compreensão dos aspectos observáveis no processo da investigação, que consta de um estudo de natureza interventiva que, segundo Teixeira e Megid Neto (2017), visa 
planejamento, aplicação e análise de dados do processo, com ênfase nas contribuições e/ou limites do fenômeno observado.

O campo empírico foi o Laboratório de Ciências de uma escola da rede pública de ensino, em São Bento do Una, Agreste Pernambucano. O estudo foi realizado com seis estudantes, definidos(as) por apresentarem dificuldades diante de situações inerentes ao cotidiano escolar que exijam articulação entre o conhecimento científico e contextos diversos, além de apresentarem disponibilidade para participação no estudo. Ressaltamos que a pesquisa, foi submetidoa à apreciação pelo Comitê de Ética em Pesquisa (CEP) da instituição envolvida.

\section{Instrumentais da pesquisa e critérios para análise de dados}

Para atender ao objetivo de identificar se os(as) estudantes, conseguiam realizar inferências apropriadas quando da compreensão de fenômenos cotidianos relacionados à corrosão, foram utilizadas entrevistas semiestruturadas a priori e a posteriori. Segundo Manzini (2004) tal instrumento constitui-se de um roteiro com perguntas orientadoras que são complementadas de acordo com as circunstâncias surgidas durante a entrevista.

Para identificar situações em que fossem estabelecidas pelos(as) estudantes conexões coerentes entre conceitos químicos e o contexto proposto, utilizamos a observação participante, que na concepção de Chizzotti (2010, pág. 90) "é obtida por meio do contato direto do pesquisador com o fenômeno observado, para recolher as ações dos atores em seu contexto natural, a partir de sua perspectiva e seus pontos de vista". As entrevistas semiestruturadas, bem como a observação participante foram registradas em áudios para posterior análise.

Os materiais caracterizados como corpus de análise foram apreciados de acordo com procedimentos de análise de conteúdo conforme Bardin (2011). Para tanto, foi realizada fragmentação dos 
materiais em unidades de significado, seguida de categorização dessas unidades. Três categorias de análise emergiram do curso do estudo, a saber: Compreensões acerca da corrosão; Associação entre corrosão e reatividade; Compreensões acerca do processo redox. Foram analisadas, as relações que os(as) estudantes estabeleceram, as dificuldades que apresentaram, os argumentos construídos e articulações de conceitos químicos para a compreensão do processo de corrosão.

\section{Proposta didática}

A intervenção foi desenvolvida a partir da aplicação de uma sequência didática (SD), constante nos documentos suplementares, na qual os(as) participantes do estudo foram submetidos(as) a dinâmicas problematizadoras, a partir de situação-problema, perspectivando, principalmente, a articulação de conceitos químicos para compreensão do tema corrosão. Para isso, recorremos à experimentação como suporte para que os(as) estudantes conseguissem articular observações experimentais e contextos diversos e, possivelmente, alcançar a significação conceitual.

\section{Análise e discussão dos dados}

Apresentaremos alguns fragmentos analíticos da observação e das entrevistas aplicadas no estudo, analisadas conforme as categorias apresentadas na metodologia. Para preservar a identidades dos(as) participantes, nomeamos os(as) estudantes pelas letras do alfabeto (A, B, C, D, E e F). A simbologia “...” representará pausa durante as falas dos(as) participantes, e, a simbologia “[...]”; omissão de texto.

\section{Categoria 1: Compreensões acerca da corrosão}


A constituição dessa categoria se deu pela análise de fragmentos que resultaram das perguntas 1 e 2 das entrevistas semiestruturadas, realizadas antes e após a intervenção.

Buscando caracterizar aspectos que remetessem à construção e/ou reconstrução dos conhecimentos dos(as) estudantes acerca do fenômeno corrosão, indagamos "1. O que você entende por corrosão?"

Antes da intervenção, identificamos dos(as) estudantes algumas dificuldades e equívocos na elaboração de tal conceito. Os(as) estudantes A, $\mathrm{D}$ e $\mathrm{F}$ apenas associaram a corrosão à ferrugem, enquanto as estudantes $\mathrm{B}$, C e E não conseguiram expressar algum conhecimento. Contudo, quando instigados(as) a pensar sobre o que significaria dizer que um material estava corroído, citando o ferro (Fe) como exemplo, a estudante B associou a corrosão à ferrugem, a estudante $\mathrm{C}$ associou à falta de utilidade do material e F se reportou à corrosão como destruição do material.

“[...] quando ele está velho demais, é ... tá enferrujado, muda de cor" (B).

"Corrosão é ... a gente utiliza, aí quando a gente não quer mais, joga..." (C). "[...] é algo que corrói, destruir... o nome já fala... corrosão, corroer" (F).

Após a intervenção, os(as) estudantes denotaram melhor abstração do fenômeno corrosão, associando-o a um desgaste do material e apresentando mudanças nas características do material, o que caracteriza uma visão mais coerentes. Algumas respostas:

"[...] tá desgastando... Porque tá sofrendo oxidação" (A).

"[...] é quando um material ... ele 'tá' se acabando, 'tá' perdendo o brilho dele, perde a cobertura de cima [...] está destruindo o material” (B).

"Ele 'tá' mudando a forma... tonalidade diferente, está se desgastando" (D).

"Está se desmanchando" (E).

"Corrosão seria algo se desfazendo, se destruindo" (F).

Nesses argumentos, percebemos o estudante A fazendo articulação coerente entre oxidação e corrosão. A estudante B, além de fazer menção ao desgaste do material, também associou tal desgaste a algumas transformações como mudança de coloração e perda de brilho, característicos 
da ocorrência de uma reação química, constante de um processo de corrosão. $\mathrm{O}$ estudante $\mathrm{D}$ caracterizou a corrosão como fenômeno mais abrangente e não apenas como ferrugem, produto da oxidação de materiais que contenham Fe em sua composição. E e F, apesar de usarem linguagem coloquial, associaram o fenômeno à deterioração do material.

Até o momento, percebemos importante evolução conceitual acerca do objeto de estudo, por parte dos(as) estudantes, pois, inicialmente, somente uma estudante conseguiu associá-la à deterioração do material. Em síntese, inferimos alinhamento conceitual com Gentil (1998) acerca do fenômeno corrosão, que se traduz no uso de termos como "destruindo", "desgastando", "desmanchando", "se desfaz", aproximando-se à definição do fenômeno como a deterioração de um material pela interação com o meio, resultando em alterações como o desgaste.

Assim, pensamos que as inquietações provocadas nos(as) estudantes durante a intervenção, por meio da problematização, contribuíram para melhor compreensão do fenômeno em estudo, indícios de reconstrução do conhecimento científico, consoante à perspectiva de Francisco Júnior, Ferreira e Hartwig (2008).

Pretendendo identificar se os(as) estudantes conseguiam realizar inferências apropriadas quando da compreensão de fenômenos cotidianos relacionados à corrosão, fizemos o questionamento "2. Você consegue identificar a corrosão em alguma situação do cotidiano?" Desse questionamento surgiram as colocações:

“[...] praia, a maresia...por causa do sal [...] o ferro? Enferruja! [...] mesa, portão, carro[...]" (A).

"[...] como a corrosão do ferro, né?! ... nós testamos e teve corrosão... magnésio teve 'num' foi?! ...zinco também, o que não teve foi a platina” (B).

“Em portões, carros, todo objeto metálico” (D).

"[...] material de construção [...] portão também, prego[...]" (E).

Percebemos os(as) estudantes em aparente processo de reflexão acerca da atividade experimental em que simulamos a oxidação, sugerindo 
associação entre a corrosão e o processo redox, além de articulação com a suscetibilidade de utensílios domésticos e de materiais de construção à corrosão. Assim, inferimos alinhamento com Suart (2014), uma vez que a atividade experimental propiciou integrar ação e reflexão e que os estudantes foram instigados a discutir, analisar e interpretar os resultados a partir da articulação de conceitos, fomentando a significação conceitual.

A caracterização da maresia como fenômeno do cotidiano associado à corrosão, bem como o exemplo da platina $(\mathrm{Pt})$ como material resistente à corrosão, remetem à apropriação dos conceitos construídos durante as dinâmicas propostas. Caracterizamos, portanto avanço no estado de compreenção dos estudantes, em oportuno alinhamento com Zanon e Uhmann (2012), quando sugerem que a experimentação tem como função didática auxiliar os(as) estudantes na compreensão de conceitos relacionados aos fenômenos estudados, com o intuito de significar tais conceitos. Baseado em Ausubel (1982, apud Pelizzari et al., 2002), pensamos, que as novas informações apresentadas durante a intervenção, possivelmente, foram ancoradas de forma substancial às estruturas cognitivas dos estudantes.

\section{Categoria 2: Associação entre corrosão e reatividade}

Nessa categoria, procuramos identificar situações em que fossem estabelecidas pelos(as) estudantes conexões coerentes entre conceitos químicos e o contexto proposto. Ressaltamos que a constituição dessa categoria se deu pela análise dos fragmentos obtidos das entrevistas semiestruturadas, que foram realizadas após ações programadas para a intervenção e da observação participante.

Tal categoria sugere abstração de conceitos químicos em articulação com o tema em estudo por parte dos(as) estudantes e resultou das questões "3. Todos os materiais podem sofrer corrosão? Explique!" e "4. Que 


\section{associações podem ser feitas entre a corrosão e fenômenos químicos?"}

da entrevista semiestruturada e dos registros da observação participante.

Os estudantes A e D e a estudante E associaram a corrosão de um material ao fato dele ser reativo, o que chamaram de ser "reagente". O estudante A ressaltou o fato de alguns metais não apresentarem tendência à doação de elétrons, fazendo diferenciação entre metais que sofrem corrosão, como magnésio $(\mathrm{Mg})$, zinco $(\mathrm{Zn})$ e alumínio $(\mathrm{Al})$ e metais menos reativos, excessão às propriedades periódicas, como a Pt. Quando pedimos que ele comparasse o Fe e a Pt em termos de oxidação, ele afirmou:

"[...] na oxidação ele "tá" doando o elétron[...]”, referindo-se ao Fe e “[...] platina não apresenta tendência à doação de elétrons" (A).

O estudante D, que havia associado inicialmente a corrosão aos materiais metálicos: "Eu acho assim, que ocorre isso mais com os metálicos, tipo lata de carro, os portões, o material deles, tipo o ferro mesmo, agora plástico essas coisas não," passou a argumentar que nem todo metal sofreria corrosão, citando exemplos:

“O que nós 'tava' estudando mesmo [...] não sofre... o ouro... porque eles são menos reagentes" (D).

A estudante $\mathrm{F}$, aparentemente baseada na fila de reatividade, foi ainda mais enfática:

"Não... tem uns materiais como a platina e o cobre, que são mais nobres, [...] aí eles são menos reativos, aí quando ele é menos reativo ele não tem facilidade de oxidar e corroer" (F).

A estudante E, quando questionada sobre a diferença entre o átomo do metal Fe, que sofre corrosão e outro que não sofre, conseguiu fazer associação coerente entre corrosão e reatividade.

\section{"[...] porque o ferro é mais reagente" (E).}

Nos diálogos estabelecidos entre os(as) estudantes, para compreensão acerca da relação entre corrosão e reatividade, os(as) estudantes associaram as características redox à estrutura submicroscópica dos metais, após a leitura de texto e simulação de 
átomos/íons com um software. Eles citaram prótons, nêutrons e elétrons, indicando as cargas elétricas de prótons e elétrons.

$\mathrm{Na}$ simulação do íon hidrogênio $\left(\mathrm{H}^{+}\right)$, utilizando o software, ressaltamos que o átomo de hidrogênio deveria ficar neutro e o estudante $\mathrm{A}$ sugeriu: "Coloca uma negativa[...] o elétron," demonstrando compreensão que no átomo a quantidade de prótons se iguala a de elétrons.

$\mathrm{Na}$ montagem do átomo de hélio eles já conseguiram compreender como produzir um íon a partir de um átomo neutro, assim como identificaram a região central como núcleo, contendo prótons e nêutrons, estando os elétrons na região externa ao núcleo. Na montagem do átomo de lítio, pedimos que observassem se havia diferença com relação aos átomos montados anteriormente, então a estudante F comentou: "Olha! O elétron não está na mesma linha! [...]". Durante a discussão do modelo atômico de Bohr, quando questionamos se o átomo de lítio seria maior que o átomo de hélio, a estudante E afirmou: "[...] maior, ele tem mais camadas."

Percebemos que a resposta da estudante E não levou em consideração que para esse raciocínio, os átomos deveriam estar no mesmo grupo. Porém, mais adiante, na construção do conceito de raio atômico observamos que os(as) estudantes compreenderam facilmente o sentido de aumento do raio num grupo da tabela periódica conforme aumenta o número de camadas no átomo, e no período, associaram a diminuição do raio a interações mais intensas em átomos com mais elétrons: "um deles tem mais elétrons, logo trata-se de um átomo menor... mais interações", abordagem da estudante E.

Durante a experimentação, em que foi simulada a redução de cobre $(\mathrm{Cu})$, ao questionarmos o que aconteceu com o Fe, eles responderam que sofreu oxidação e sobre a mudança na estrutura do átomo a estudante $\mathrm{F}$ sugeriu que ele doou elétrons. Questionamos o que seria necessário para essa doação e a mesma estudante afirmou: “[...] depositar energia." Daí discutimos o conceito de energia de ionização e eles(as) sugeriram que seria mais fácil retirar elétron de um átomo grande e relacionaram o sentido de aumento da energia de ionização na tabela periódica, com a atividade 
experimental, de onde surgiu o argumento: "Quando o ferro doou elétron, ele saiu dessa camada e foi para o cobre."

Dos diálogos, inferimos que os(as) estudantes já apresentavam indícios da compreensão da transferência de elétrons, associando a energia de ionização ao raio atômico.

Os conceitos de eletronegatividade e eletropositividade foram sendo construídos em diálogo com as ideias de reatividade apresentadas pelos estudantes, para auxiliá-los na compreensão da transferência de elétrons. Num desses momentos, flagramos a estudante $\mathrm{F}$ apresentando definição equivocada de eletropositividade: “[...] a atração do próton.” Tal equívoco foi superado, após enfatizarmos a tendência de doar elétrons: " $n a$ eletropositividade vai expulsar."

Acerca do $\mathrm{Mg}$, que eles classificaram como muito reativo na atividade experimental, os(as) estudantes conseguiram responder que se tratava de um átomo grande, com baixa energia de ionização e eletropositivo. Quando perguntamos o que significaria ele ser eletropositivo, o estudante $\mathrm{D}$ respondeu que teria facilidade em doar elétrons. Percebemos que apesar de o estudante fazer mensão à reatividade baseada em propriedades periódicas, o mesmo não consegue perceber a platina como excessão. Contudo, após a discussão sobre as características peculiares dos metais de transição, como a presença do subnível d, os(as) estudantes sugeriram que a Pt seria um material menos reativo, por isso sua utilização na placa para reestruturação óssea.

Ficou evidente que no curso do estudo foi trilhado um longo percurso para que os estudantes pudessem significar o conhecimento e não apenas memorizar informações ou abstraí-las de forma acrítica, consoante a Zanon e Uhmann (2012) e Suart (2014) sobre o papel do(a) professor(a) na mediação do processo de ensino-aprendizagem, como o responsável por criar situações que exigissem reflexão durante a investigação e pela inserção da problematização, atrelando observações e 
discussões teóricas para que os estudantes construíssem argumentos e hipóteses para a solução da situação-problema.

\section{Categoria 3: Compreensões acerca do processo redox}

A constituição dessa categoria se deu pela análise dos dados da entrevista, realizada após a intervenção. Vale ressaltar que para melhor consistências dos resultados também recorremos aos dados da observação participante.

A elaboração dessa categoria remete à contribuição da experimentação para compreensão da corrosão em articulação com conceitos químicos. Assim, ao indagarmos "5 Como você descreveria o fenômeno observado (desgaste de um metal) em nível submiscroscópico?”, surgiram as colocações:

"[...] está doando o elétron [...] na oxidação doa elétron e na redução ganha [...] o ferro tomou o lugar do cobre” (A).

"As partículas estão ficando agitadas... Elas saem e vão para outro" (B).

"[...] perda de elétrons... para a substância que ele está interagindo [...] isso a gente viu... oxirredução! [...] a oxidação é a perda, como no ferro” (D).

"[...] na corrosão o material é oxidado [...] perda de elétrons... aí seria tipo do ferro para alguma substância [...] é a redox... uma substância vai ter oxidação e a outra vai ter a redução" (F).

Dos argumentos apresentados, percebemos que os(as) estudantes recorrem à atividade experimental, para explicar as reações redox que ocorrem na corrosão, demonstrando que a experimentação pode ter cumprido com sua função de auxiliar os(as) estudantes na compreensão e significação dos conceitos químicos associados à corrosão, contribuindo no processo investigativo, em oportuno alinhamento com Galiazzi e Gonçalves (2004) e Suart (2014). 
Embora a estudante $B$ não tenha explicado a transferência de elétrons entre os átomos durante a reação redox, fez associação coerente entre a corrosão e a perda/ganho de elétrons pelo átomo.

Da estudante $\mathrm{F}$ percebemos melhor abstração de conceitos químicos, em articulação coerente entre a corrosão e o processo redox. Ficou evidente que ela utiliza, tais articulações para fundamentar as reações de transferência de elétrons que ocorrem na corrosão. Ressaltamos, ainda, que o fato de a estudante ter citado o Fe como exemplo da oxidação, converge para a atividade experimental em que foi simulada a redução.

O estudante A sugeriu que na corrosão o material se desgasta porque sofre oxidação e ao tentar associar a corrosão com algum fenômeno químico, acrescentou a ocorrência da redução, em processo simultâneo à oxidação, definindo o processo como redox. Salientamos ainda que apesar de usar linguagem coloquial, o estudante demonstrou compreensão da reação de simples troca ocorrida na reação redox, simulada na experimentação.

Durante a experimentação, o estudante $\mathrm{D}$, ao ser questionado sobre a perda/ganho de alguma partícula do átomo do material que sofre corrosão, respondeu que seria a perda de elétrons, os quais seriam transferidos.

A estudante E, ao ser questionada sobre a possibilidade de impedir a reação redox, sugeriu que não haveria tendência à transferência de elétrons entre as substâncias em contato, caso se tratasse da mesma substância ou de substâncias que não fossem reativas.

Durante a utilização de cartas na construção das equações químicas para representação matemática dos reagentes e produtos das reações redox observadas, simulamos a reação de redução, solicitando que encontrassem o sulfato de cobre. Nesse momento da intervenção percebemos indícios do trabalho cooperativo entre os estudantes, coadunando com o pensamento de Galiazzi e Gonçalves (2004) ao associarem a experimentação ao trabalho cooperativo e à socialização dos estudantes, bem como ao desenvolvimento de habilidades de argumentação. 
Quando indagamos o que teria ocorrido na reação, os(as) estudantes A, D e F demonstraram a compreensão da reação de oxirredução como a transferência de elétrons entre $\mathrm{Cu}$ e $\mathrm{Fe}$, evidenciada nas respostas: "Teve aquela coisa de um perder elétrons pro outro..." (F); "Redox... redox!” (A); "Cobre sofre redução" (D).

Para auxiliá-los na compreensão da reação de deslocamento, abordamos as reações químicas em termos do rompimento e formação de novas ligações. Questionamos o que aconteceria com o $\mathrm{Fe}$ e a estudante F, embora tenha usado linguagem coloquial, demonstrou apropriação quanto a reações de simples troca: "O ferro 'tá' sozinho, mas ele é reativo, ele não gosta de ficar sozinho... o cobre consegue ficar mais sozinho que ele [...] ele vai chutar o cobre e vai tomar o lugar dele" (F).

Novamente houve cooperação entre eles para representar os produtos da reação, e evidências de compreensão de que houve uma troca entre o $\mathrm{Fe}$ e o $\mathrm{Cu}$, como sugerido na fala de $\mathrm{B}$ : "[...] porque o cobre se deslocou do lugar dele para outro." Reiterando que o Fe conseguiu deslocar o $\mathrm{Cu}$ por ser mais reativo que ele.

Após a determinação do nox das espécies, pedimos que comparassem os valores para o $\mathrm{Fe}$ nos reagentes e nos produtos da equação e a estudante F disse: "Ele não tinha nada! [...] tinha nox zero e foi para... +2". Sobre o significado dessa variação a estudante $\mathrm{E}$, relembrando as interações entre as cargas elétricas no átomo, acrescentou: "perdeu?"

Quando solicitamos que os(as) estudantes anotassem a equação construída, eles(as) apresentaram dificuldades na identificação do estado de agregação do $\mathrm{Cu}$. Daí relembramos que o Fe tinha deslocado o $\mathrm{Cu}$ e assim a estudante E disse: "Então ele ficou sólido?" Isso ajudou a estudante F a identificar o material que tinha se formado sobre o prego na atividade experimental que simulou a redução: "É o cobre? Passada!", referindo-se ao fato de o $\mathrm{Cu}$ ter passado da forma iônica para metálica.

Para construção da equação que representava a oxidação do $\mathrm{Fe}$ pelo hidrogênio, utilizando as cartas, a estudante $\mathrm{F}$ comentou: "Tem que 
encontrar o que é menos reativo que o ferro." Ao comparar o Fe e o hidrogênio na fila de reatividade, evidenciamos abstração do processo de transferência de elétrons entre as espécies na fala de A: "O ferro é mais reativo... vai acontecer a mesma coisa que aconteceu com o cobre", resgatando a conclusão deles de o Fe não poder ser utilizado numa placa por participar do processo de oxirredução. Ao questionarmos se também seria uma reação de deslocamento, a estudante E comentou: "É... que trocou aqui[...], referindo-se ao Fe e ao hidrogênio. A fala da estudante demonstra que estava apropriada do conceito de reação de deslocamento, visto que percebeu a troca ocorrida.

Ao pedirmos que lançassem hipóteses sobre o que aconteceria como consequência da interação do $\mathrm{Mg}$ com o hidrogênio, a estudante $\mathrm{F}$ disse acreditar que ocorreria o deslocamento do hidrogênio. Eles identificaram a oxidação do Mg e a redução do hidrogênio, percebendo a simples troca: "Ele mandou o hidrogênio embora e ficou no lugar dele."

$\mathrm{Na}$ equação que representava a oxidação do $\mathrm{Zn}$, eles já apresentaram facilidade na determinação da variação do nox e na identificação da oxidação e da redução: "Ele perdeu dois elétrons e sofreu oxidação.” Disse o estudante $\mathrm{D}$, referindo-se ao $\mathrm{Zn}$.

Quando levantamos a hipótese de oxidação do $\mathrm{Cu}$ com hidrogênio, surgiram alguns comentários: “E vai ter?! ... acho que não... não vai ter não!' Perguntamos o que aconteceu com o $\mathrm{Cu}$ na atividade experimental que simulava a oxidação e eles afirmaram que não ocorreram mudanças, então a estudante F explicou: "[...] porque ele é menos reativo que o hidrogênio." E sobre o significado de o $\mathrm{Cu}$ ser menos reativo que o hidrogênio, o estudante $A$ sugeriu que a reação não ocorreu. Ao questionarmos sobre a estabilidade da Pt surgiram comentários semelhantes: "Vai fazer a mesma coisa, né?... não vai reagir."

Desse diálogo, evidenciamos dos(as) estudantes compreensão acerca da reatividade dos metais e enfatizamos a conclusão deles de que Fe não podria substituir $\mathrm{Pt}$, por ser mais reativo. Pela fila de reatividade, eles 
concluíram ainda que o uso de Pt na reconstrução óssea se deve a sua baixa reatividade. Entendemos que o presente estudo dialoga com Francisco Júnior (2008), quando entende que o conhecimento se constrói em um processo dialógico, em que o(a) docente, por meio da problematização, oportuniza o(a) estudante a pensar e discutir a relação de conceitos químicos de maneira desfragmentada e contextualizada.

\section{Conclusão}

Da análise, identificamos aspectos relativos à compreensão dos(as) estudantes acerca da corrosão, a partir de articulações do conhecimento químico para resolução de uma situação-problema. No curso do estudo eles(as) conseguiram estabelecer conexões coerentes entre o contexto proposto e os conceitos químicos abordados, realizando inferências apropriadas em meio à discussão sobre o comportamento dos metais. Tais fatos nos remetem à pergunta da pesquisa: Como o uso da experimentação, em atividades problematizadoras, poderia contribuir para a significação de conceitos químicos na compreensão do fenômeno corrosão, junto a um grupo de estudantes do ensino médio?

Os instrumentos utilizados para construção dos dados e os referenciais teóricos que embasaram a análise permitiram-nos fazer algumas inferências que serão descritas a seguir.

$\mathrm{Na}$ categoria "Compreensões acerca da corrosão" percebemos dos(as) estudantes, importante evolução conceitual acerca do objeto de estudo, uma vez que após a intervenção eles demonstraram melhor abstração, associando a corrosão ao desgaste do material. Passaram a entender a ferrugem como produto da corrosão do ferro, e associaram a corrosão à oxidação do material, inclusive, ferro, além de fazerem associações ao desgaste de outros materiais corrosiveis do cotidiano.

A categoria "Associação entre corrosão e reatividade" sugere que os(as) estudantes puderam significar o conhecimento, ao articular 
conceitos, como estrutura atômica e propriedades periódicas, oxidação e redução, para a compreensão da corrosão, bem como para associar a estabilidade de um metal ao fato de não apresentar tendência à doação de elétrons por meio da oxidação.

Da categoria "Compreensões acerca do processo redox", evidenciamos a compreensão dos(as) estudantes acerca da reatividade dos metais e dos processos de transferência de elétrons em reações redox, o que os(as) permitiu concluírem que o ferro não seria uma opção como substituo da platina na construção de placas para reconstrução óssea, atribuindo essa evidência ao fato de o ferro ser um metal muito reativo. Pela fila de reatividades, eles(as) concluíram ainda que a platina é o metal mais resistente entre os metais estudados, e sugeriram que esse deve ser o motivo pelo qual esse metal é utilizado para auxiliar na reconstrução.

Frente ao exposto, sugerimos que a intervenção, contribuiu para os processos cognitivos e argumentativos desenvolvidos, nos quais a experimentação se fez propícia às articulações entre o conhecimento químico e o contexto estudado, a partir das interações promovidas em meio à problematização, conduzindo os(as) estudantes a alcançarem a significação conceitual de forma crítica.

Salientamos que a postura assumida pelo(a) docente, na promoção do diálogo e mediação das interações, na experimentação investigativa é aspecto diretamente atrelado aos resultados obtidos na pesquisa. Doravante, acreditamos ser relevante maiores investidas na formação continuada de docentes de Química da educação básica, que possam contribuir para que esses profissionais atuem com propriedade na condução de atividades em propostas semelhantes a que foi apresentada nesse estudo.

\section{Referências}

AUSUBEL, D. P. The psychology of meaningful verbal learning. New York: Grune \& Stratton, 1963.

BARDIN, l. Análise de conteúdo. Lisboa: Edições 70, 2011. 
BINSFELD, S. C.; AUTH, M. A. A experimentação no ensino de ciências da educação básica: constatações e desafios. In: ENCONTRO NACIONAL DE PESQUISA EM EDUCAÇÃO EM CIÊNCIAS, 8., 2011, Campinas. Anais [...]. Campinas: UNICAMP, 2011. p. 1-10.

BRASIL. Ministério da Educação, Secretaria de Educação Média e Tecnológica. $P C N+$ Ensino médio: orientações educacionais complementares aos Parâmetros Curriculares Nacionais - Ciências da Natureza, Matemática e suas Tecnologias. Brasília, DF: Ministério da Educação, 2002. 141 p.

CACHAPUZ, A.; GIL-PEREZ, D.; CARVALHO, A. M. P.; PRAIA, J.; VILCHES, A. (org.). A necessária renovação do ensino das ciências. São Paulo: Cortez, 2005.

CHASSOT, A. Alfabetização científica: questões e desafios para a educação. 6. ed. Ijuí: Unijuí, 2014.

CHIZZOTTI, A. Pesquisa em ciências humanas e sociais. 11. ed. São Paulo: Cortez, 2010.

FRANCISCO JÚNIOR, W. E. Uma abordagem problematizadora para o ensino de interações intermoleculares e conceitos afins. Química Nova na Escola. São Paulo, n. 29, p. 20, fev/ago. 2008.

FRANCISCO JÚNIOR, W. E.; FERREIRA, L. H.; HARTWIG, D. R. Experimentação problematizadora: fundamentos teóricos e práticos para a aplicação em aulas de aula de ciências. Química Nova na Escola. São Paulo, n. 30, p. 34-41, set/nov. 2008.

GALIAZZI, M. C.; GONÇALVES, F. P. A natureza pedagógica da experimentação: uma pesquisa na licenciatura em Química. Química Nova. São Paulo, v. 27, n. 2, p. 326-331, dez. 2002/ ago. 2004. DOI: https://doi.org/10.1590/s0100-40422004000200027.

GENTIL, V. Corrosão. 3. ed. Rio de Janeiro: LTC, 1998.

GIANI, K. A experimentação no ensino de ciências: possibilidades e limites na busca de uma aprendizagem significativa. 2010. 190 f. Dissertação (Mestrado Profissional em Ensino de Ciências) - Universidade de Brasília, Brasília.

GONÇALVES, F. P. O texto de experimentação na educação em química: discursos pedagógicos e epistemológicos. 2005. 168 f. Dissertação (Mestrado em Educação Científica e Tecnológica) - Universidade Federal de Santa Catarina, Florianópolis, 2005. 
GUIMARÃES, C. C. Experimentação no ensino de química: caminhos e descaminhos rumo à aprendizagem significativa. Química Nova na Escola, São Paulo, v. 31, n. 3, p. 198-200, ago. 2007/ago. 2009.

KATO, D. S.; KAWASAKI, C. S. As concepções de contextualização do ensino em documentos curriculares oficiais e de professores de ciências. Ciência e Educação, Bauru, v. 17, n. 1, p. 35-50, set. 2010/2011. DOI: https://doi.org/10.1590/S1516-73132011000100003.

LIMA, J. F. L.; PINA, M. S. L.; BARBOSA, R. M. N.; JÓFILI, Z. M. S. A contextualização no ensino de cinética química. Química Nova na Escola, São Paulo. São Paulo, n. 11, p. 26-29, 2000.

MANZINI, E. J. Entrevista semi-estruturada: análise de objetivos e de roteiros. In: SEMINÁRIO INTERNACIONAL SOBRE PESQUISA E ESTUDOS QUALITATIVOS, 2., 2004, Bauru. Anais [...]. Bauru: USC, 2004. p. 1-10.

MEIRIEU, P. Aprender... sim, mas como? 7. ed. Porto Alegre: Artmed, 1998.

MELO, C. C.; OLIVEIRA, R. C. B.; SOUZA, A. N. A utilização da experimentação como aporte de atividades problematizadoras para a significação de conceitos químicos no ensino médio. Debates em Educação, Maceió, v. 11, n. 24, p. 84-105, mai/ago. 2019. DOI: http://dx.doi.org/10.28998/2175-6600.2019v11n24p84-105.

MERÇON, F.; GUIMARÃES, P. I. C.; MAINIER, F. B. Corrosão: um exemplo usual de fenômeno químico. Química Nova na Escola, São Paulo, n. 19, p. 11-14, set. 2003/maio. 2004.

MERÇON, F.; GUIMARÃES, P. I. C.; MAINIER, F. B. Sistemas experimentais para o estudo da corrosão em metais. Química Nova na Escola, São Paulo, v. 33. n. 1. p. 57-60, ago. 2010/fev. 2011.

MOREIRA, M. A.; MASINI, E. F. S. Aprendizagem significativa: a teoria de David Ausubel. 1. ed. São Paulo: Centauro, 2001.

MOREIRA, M. A. Aprendizagem Significativa: da visão clássica à visão crítica. In: ENCONTRO NACIONAL DE APRENDIZAGEM SIGNIFICATIVA, 1., 2005, Campo Grande. Atas [...]. Campo Grande: UNIDERP, 2005.

MOREIRA, M. A. Aprendizaje Significativo Crítico. 2. ed. Indivisa, Boletín de Estudios e Investigación, Madrid, 2 ed. n. 6, p. 83-101, 2010.

OLIVEIRA, R. C.; HARTWIG, D. R.; FERREIRA, L. H. Ensino experimental de química: uma abordagem investigativa contextualizada. Química Nova na Escola, São Paulo, v. 32, n. 2, p. 101-102, set. 2009/mai. 2010. 
PELIZZARI, A.; KRIGL, M. L.; BARON, M. P.; FINCK, N. T. L.;

DOROCINSKI, S. I. Teoria da aprendizagem significativa segundo Ausubel. PEC, Curitiba, v. 2, n. 1, p. 37-42, jul. 2001/jul. 2002.

POZO, J. I.; CRESPO, M. A. G. A aprendizagem e o ensino de ciências: do conhecimento cotidiano ao conhecimento científico. 5. ed. Porto Alegre: Artmed, 2009.

SANJUAN, M. E. C.; SANTOS, C. V.; MAIA, J. O.; SILVA, A. F. A; WHARTA, E. J. Maresia: uma proposta para o ensino de eletroquímica. Química Nova na Escola, São Paulo, v. 31, n. 3, p. 190-197, abr. 2008/ ago. 2009.

SANTOS, A. O., SILVA, R. P., ANDRADE D., \& LIMA, J. P. M. Dificuldades e motivações de aprendizagem em Química de alunos do ensino médio investigadas em ações do (PIBID/UFS/Química). Scientia plena, Aracajú, v.9, n. 7, p. 1-6. Dez. 2012/mar. 2013.

SILVA, R. R.; MACHADO, P. F. L; TUNES, E. Experimentar Sem Medo de Errar. In: SANTOS, W. L. P.; MALDANER, O. A (Orgs.). Ensino de Química em Foco. 1 ed. Ijuí: Unijuí, 2010. p. 231-261.

SUART, R. C. A experimentação no ensino de química: conhecimento e caminhos. In: SANTANA, E.; SILVA, E. (orgs.). Tópicos em ensino de química. São Carlos: Pedro \& João Editores, 2014. p. 63-78.

TEIXEIRA, Paulo M. M.; MEGID NETO, Jorge. Uma proposta de tipologia para pesquisas de natureza interventiva. Ciência \& Educação, Bauru, v. 23, n. 4, p. 1055-1076, 2017. DOI: https://doi.org/10.1590/1516731320170040013.

WARTHA, E. J.; SILVA, E.; BEJARANO, N. R. R. Cotidiano e contextualização no ensino de Química. Química Nova na Escola, São Paulo, v. 35, n. 2, p. 84-91. Ag. 2012/mai. 2013.

ZANON, L. B.; UHMANN, R. I. M. O desafio de inserir a experimentação no ensino de ciências e entender a sua função pedagógica. In: ENCONTRO NACIONAL DE ENSINO DE QUÍMICA, 16., ENCONTRO DE EDUCAÇÃO QUÍMICA DA BAHIA, 10., Salvador. Anais [...]. Salvador: UFBA, 2012. 